\title{
Article \\ Ethanol Dehydrogenation to Acetaldehyde over Co@N-Doped Carbon
}

\author{
Aleksey N. Chernov ${ }^{1}$, Tatiana V. Astrakova ${ }^{2}$, Konstantin Yu. Koltunov ${ }^{1}{ }^{(D)}$ and Vladimir I. Sobolev ${ }^{1, *}$ \\ 1 Boreskov Institute of Catalysis, Russian Academy of Sciences, Pr. Akademika Lavrentieva, 5, \\ 630090 Novosibirsk, Russia; anch@catalysis.ru (A.N.C.); koltunov@catalysis.ru (K.Y.K.) \\ 2 Department of Natural Sciences, Novosibirsk State University, Pirogova, 2, 630090 Novosibirsk, Russia; \\ t.astrakova@g.nsu.ru \\ * Correspondence: visobo@catalysis.ru; Tel.: +7-383-3269765
}

Citation: Chernov, A.N.; Astrakova, T.V.; Koltunov, K.Y.; Sobolev, V.I. Ethanol Dehydrogenation to Acetaldehyde over Co@N-Doped Carbon. Catalysts 2021, 11, 1411. https://doi.org/10.3390/ catal11111411

Academic Editors: Valérie Caps and Luca Bernardi

Received: 29 October 2021

Accepted: 19 November 2021

Published: 21 November 2021

Publisher's Note: MDPI stays neutral with regard to jurisdictional claims in published maps and institutional affiliations.

Copyright: (c) 2021 by the authors. Licensee MDPI, Basel, Switzerland. This article is an open access article distributed under the terms and conditions of the Creative Commons Attribution (CC BY) license (https:// creativecommons.org/licenses/by/ $4.0 /)$.

\begin{abstract}
Cobalt and nitrogen co-doped carbon materials (Co@CN) have recently attracted significant attention as highly efficient noble-metal-free catalysts exhibiting a large application range. In a similar research interest, and taking into account the ever-increasing importance of bioethanol as a renewable raw material, here, we report the results on ethanol dehydrogenation to acetaldehyde over Co@NC catalysts. The catalyst samples were synthesized by a variety of affordable techniques, ensuring generation of various types of Co species incorporated in carbon, such as subnanosized cobalt sites and nano-sized particles of metallic cobalt and cobalt oxides. The catalytic activity was tested under both oxidative and non-oxidative gas-phase conditions at $200-450{ }^{\circ} \mathrm{C}$ using a fixed-bed flow reactor. The non-oxidative conditions proved to be much more preferable for the target reaction, competing, however, with ethanol dehydration to ethylene. Under specified reaction conditions, ethanol conversion achieved a level of $66 \%$ with $84 \%$ selectivity to acetaldehyde at $400{ }^{\circ} \mathrm{C}$. The presence of molecular oxygen in the feed led mainly to deep oxidation of ethanol to $\mathrm{CO}_{\mathrm{x}}$, giving acetaldehyde in a comparatively low yield. The potential contribution of carbon itself and supported cobalt forms to the observed reaction pathways is discussed.
\end{abstract}

Keywords: cobalt-nitrogen-carbon catalyst; heterogeneous catalysis; ethanol conversion; dehydrogenation; acetaldehyde

\section{Introduction}

Ethanol is one of the most important biomass-derived platform molecules [1,2]. Given the ongoing trend towards using bioethanol as a renewable feedstock for the production of commodity chemicals, the development of heterogeneous catalysts for the selective conversion of ethanol into acetaldehyde, ethylene, acetic acid, ethyl acetate, propylene, 1-butanol, 1,3-butadiene and other key chemical intermediates continues to be a challenge [3-5].

In particular, both oxidative and non-oxidative dehydrogenations of ethanol to obtain acetaldehyde have been extensively studied, and many catalysts have been already tested in these reactions [3-5]. It should be noted, however, that ethanol dehydrogenation is often inclined to compete with dehydration, giving ethylene. For that reason, the most efficient heterogeneously catalyzed conversion of ethanol into acetaldehyde (irrespective of oxidative or non-oxidative conditions) has been performed with supported noble-metal catalysts, exhibiting, in addition, the lowest surface acidity [3].

As an alternative route, gaining significant interest, a number of studies have used catalysts based on readily available, inexpensive transition metals deposited on a lowacidity carrier. In line with that approach, activated carbon as itself [6-11], and much more successfully, carbon doped with $\mathrm{MoO}_{3}$ or $\mathrm{Cu}$, have shown high catalytic performances in the selective non-oxidative dehydrogenation of ethanol to acetaldehyde [12-17]. For example, conversion of ethanol over $\mathrm{Cu}$ deposited on activated carbon has attained a 
level of $65 \%$ with $96 \%$ selectivity to acetaldehyde at $350{ }^{\circ} \mathrm{C}$ under gas flow reaction conditions [15], while the use of $\mathrm{Cu}$ deposited on mesoporous carbon appeared even more effective, affording acetaldehyde in a $79 \%$ yield at $280^{\circ} \mathrm{C}$ [13]. On the other hand, the use of carbon doped with such additives as $\mathrm{Ce}, \mathrm{Co}$ or Ni has shown poor results [15].

However, it is noteworthy in this regard that carbon materials doped by a combination of a transition metal ( $\mathrm{Fe}, \mathrm{Ni}, \mathrm{Cu}$, and especially $\mathrm{Co}$ ) and nitrogen have recently attracted significant interest as highly efficient noble-metal-free catalysts in a variety of applications [18-26]. Above all, liquid phase oxidative esterification of alcohols [19,27-33], oxidative dehydrogenation of 1,2,3,4-tetrahydroquinolines into quinolines [20,21], non-oxidative dehydrogenation of propane to propylene [19] and selective dehydrogenation of formic acid [34-36] catalyzed by Co@NC materials should be highlighted as quite encouraging for the use of the analogous catalysts in a gas phase ethanol-to-acetaldehyde conversion.

Notably, the Co@NC catalysts have been prepared by a variety of techniques. They were often obtained by the incipient wetness impregnation of carbon black or carbon nanotubes with cobalt(II) salts and N-ligands, followed by pyrolysis [21,22]. In addition, Co@NC can be synthesized through carbonization of cobalt-nitrogen containing metalorganic frameworks (MOFs), such as zeolitic-imidazole frameworks (ZIFs) [23,30,35]. Even more practical seems to be a synthetic approach based on a solid-state mixing of carbon black with cobalt(II) salts and N-ligands, followed by heat treatment, which can result in Co@NC catalysts of comparable activity with regard to particular reactions [36,37]. In any case, all the synthetic techniques finally require a high-temperature $\left(700-1000^{\circ} \mathrm{C}\right)$ pyrolysis of the catalyst precursor, yielding thereby quite similar materials consisting of nano-sized particles of metallic cobalt, cobalt oxides and subnanosized cobalt species. The latter proved to be atomically-dispersed $\mathrm{Co}(\mathrm{II})-\mathrm{N}_{\mathrm{x}}$ sites incorporated in graphene/graphitic carbon [35]. It is remarkable, however, that the relative content of the structural elements listed may be regulated by using special synthetic or post-synthetic approaches $[19,23,34-36]$. This, in principle, allows the establishment of which of the active sites determines the catalytic performance in any given reaction.

Herein, in continuation of our long-standing interest in the selective conversion of ethanol into value added chemicals under both oxidative and non-oxidative reaction conditions [38-40], and in order to explore further the potential applicability limits of Co@NC type catalysts, we report the findings on the catalytic activity of Co@NC materials in the ethanol dehydrogenation reaction.

\section{Results and Discussion}

\subsection{Catalysts Characterization}

Figure 1 shows the XRD patterns of as-synthesized catalysts. In the case of Co@NCGr, Co@NC-ZIF and Co@C-Gr samples, the clearly visible peaks at 44.0, 51.7 and 75.9 correspond to (111), (200) and (220) crystallographic planes of cubic Co. These peaks reflect the presence of metallic cobalt in the samples. In contrast, such peaks look very faint for

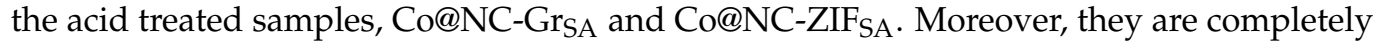
absent in the pattern of the cobalt-free NC-Gr material. The XRD pattern of Co@NC-ZIF contains also a well distinguishable set of peaks related to crystallographic planes of $\mathrm{CoO}$ and $\mathrm{Co}_{3} \mathrm{O}_{4}$ particles. The residual presence of cobalt oxides in Co@NC-ZIF is obviously related to some carbon deficiency when this material is formed during carbonization of ZIF-67. As could be expected, metallic Co is mainly formed upon the pyrolysis process, provided the amount of carbon is sufficient for the reduction of $\mathrm{Co}^{+2}$. However, with the relative lack of carbon, as in the case of ZIF-67, cobalt oxides cannot be reduced completely to $\mathrm{Co}^{0}$. Lastly, for all the catalysts two broad diffraction peaks are observed at $\sim 25$ and $44^{\circ}$, which can be assigned to a turbostratic (amorphous-graphitic) carbon [41]. 


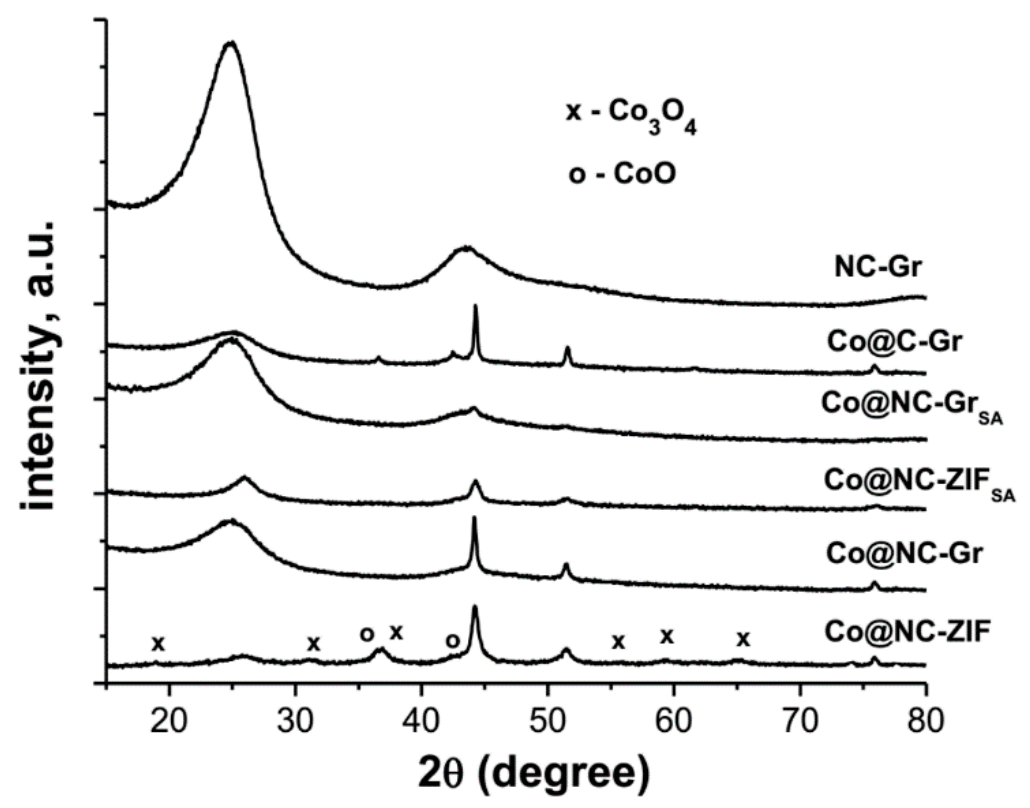

Figure 1. Powder XRD patterns of the prepared catalysts.

Though Co@NC-Gr and Co@NC-ZIF catalysts are obtained by different synthetic approaches, their TEM images look very similar except a higher proportion of cobalt nanoparticles in the latter sample (Figure S1 and Figure S2, Supplementary Materials). The nanoparticles observed are mainly $10 \div 30 \mathrm{~nm}$ size for both the catalysts, in accordance with our previous results [36,37]). Despite being enveloped by graphitic carbon, the metallic cobalt particles practically disappeared after treatment of Co@NC-Gr with sulfuric acid (Figure S3). In contrast, Co@NC-ZIF $\mathrm{IA}_{\mathrm{SA}}$ retained some parts of cobalt nanoparticles if they were in dense graphite packaging (Figure 2a,c). In addition, well-resolved fragments of $\mathrm{CoO}_{\mathrm{x}}$ are present in the catalyst (Figure 2d). That is also confirmed by EDX-STEM mapping images of $\mathrm{Co} @ \mathrm{NC}-\mathrm{ZIF}_{\mathrm{SA}}$, where location of cobalt and oxygen conglomerates definitely coincides in some cases (Figure $3 \mathrm{a}-\mathrm{c}$ ).

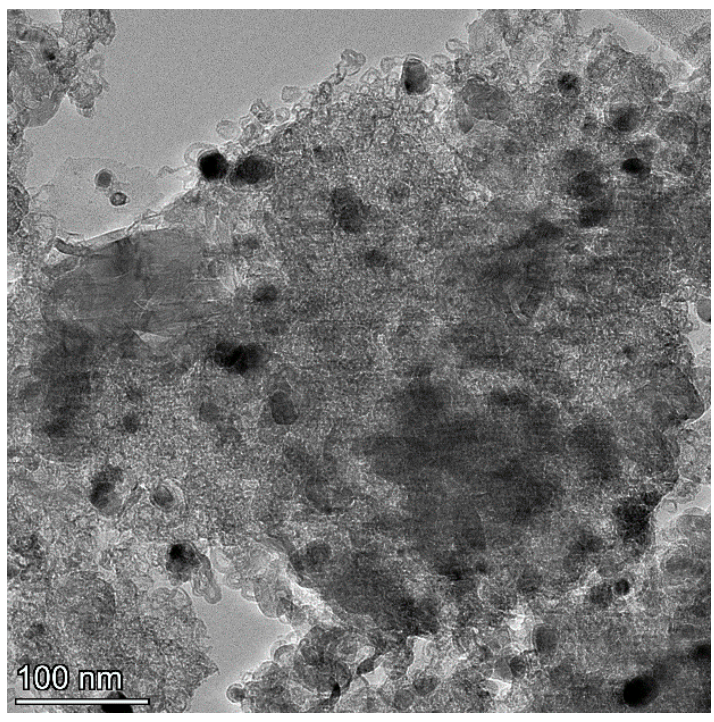

(a)

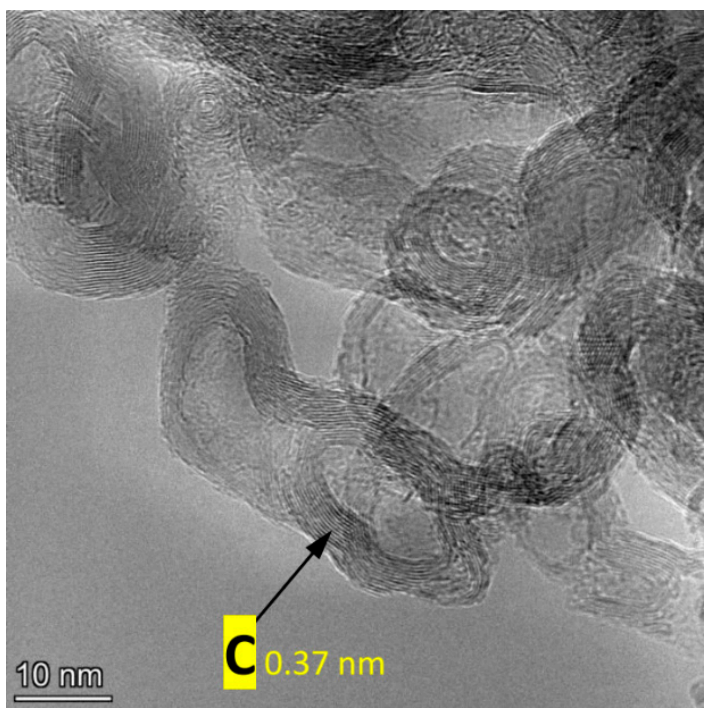

(b)

Figure 2. Cont. 


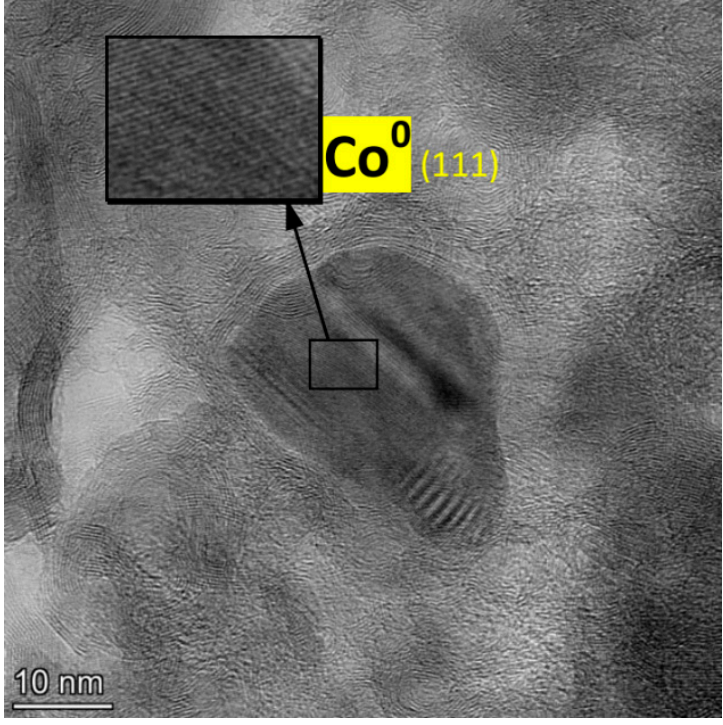

(c)

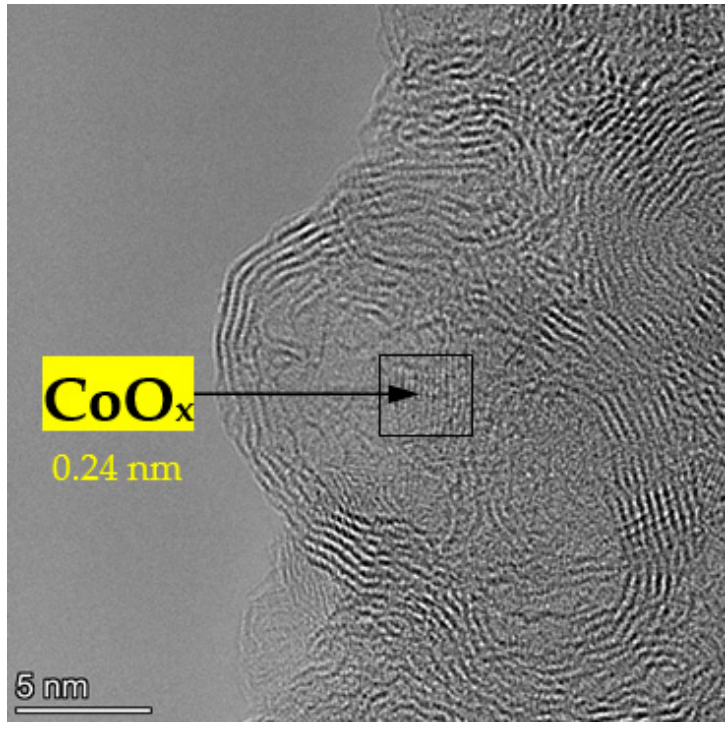

(d)

Figure 2. TEM images of Co@NC-ZIF (c) cobalt residual nanoparticle densely coated with graphite carbon; (d) the fragment containing cobalt oxides.

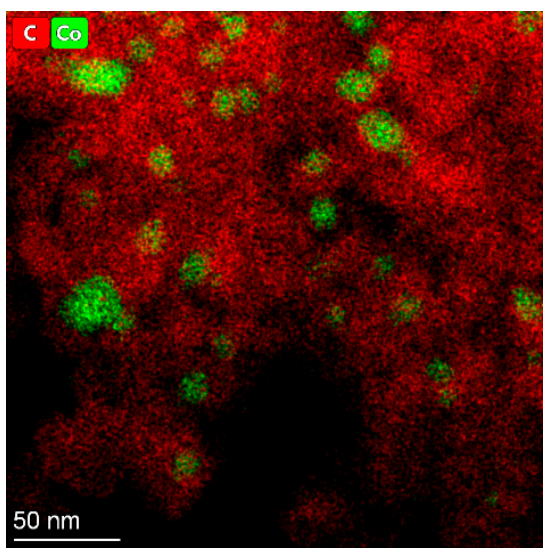

(a)

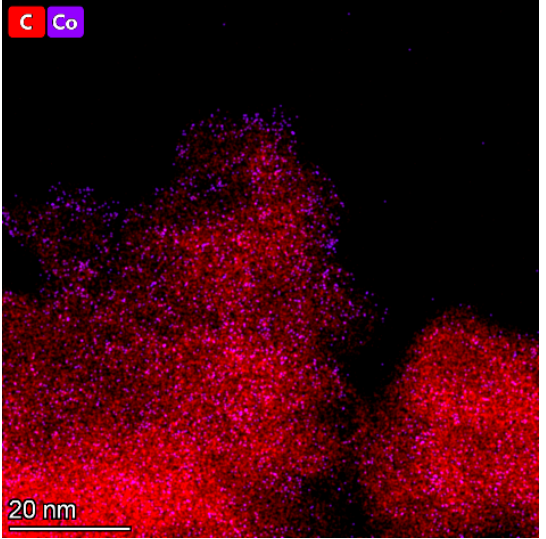

(d)

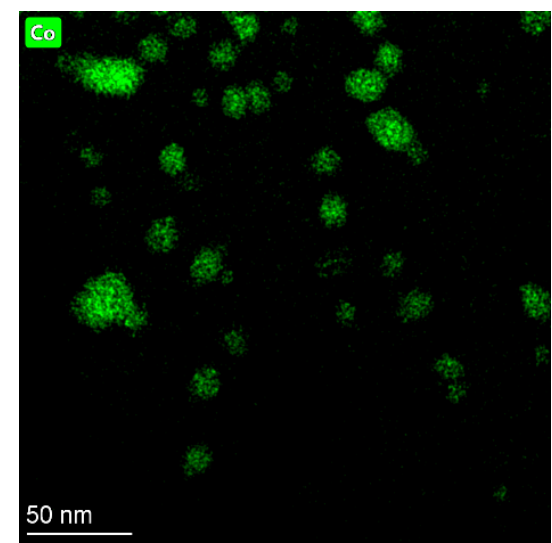

(b)

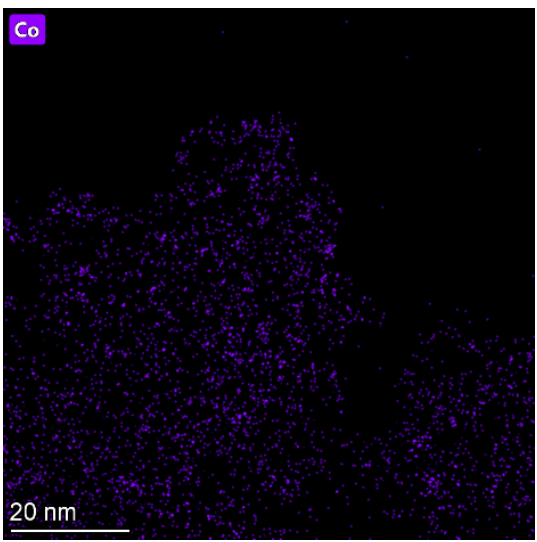

(e)

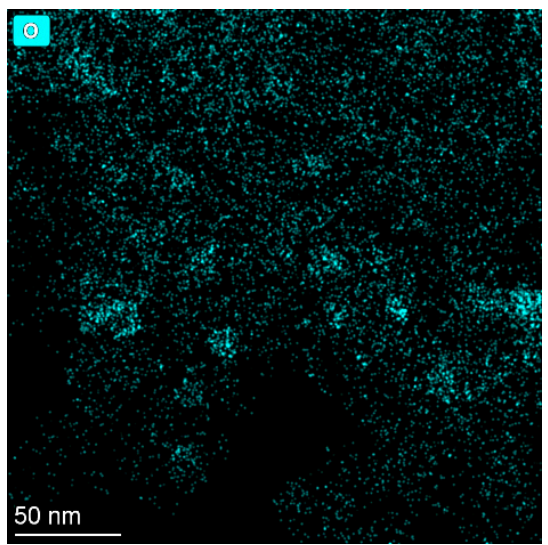

(c)

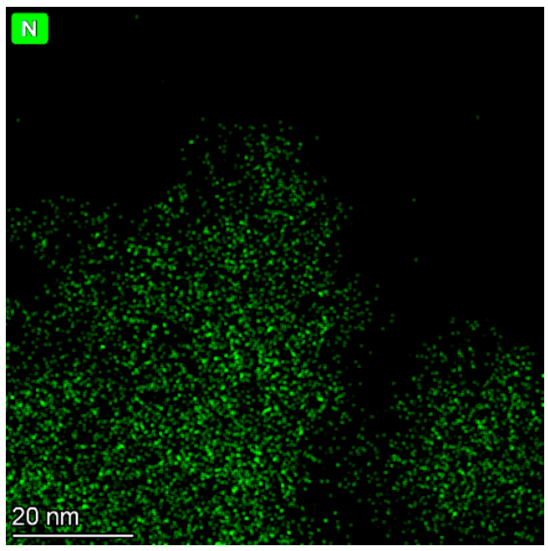

(f)

Figure 3. Selected EDX-STEM mapping images of Co@NC-ZIF $\mathrm{SA}_{\mathrm{A}}$ : (a-c) mixed C/Co, Co and O elements of a fragment containing $\mathrm{CoO}_{x} ;(\mathbf{d}-\mathbf{f}) \mathrm{Co} / \mathrm{C}, \mathrm{Co}$ and $\mathrm{N}$ elemental mapping of the catalyst area free from $\mathrm{Co}$ and $\mathrm{CoO}_{\mathrm{x}}$ nanoparticles. 
Figure $3 \mathrm{~d}-\mathrm{f}$ demonstrates STEM images of another fragment of the same sample, illustrating a uniform distribution of subnanosized Co species and nitrogen in carbon. According to EDX analysis, the atomic fraction of Co in this area is only $0.27 \%(1.33 \mathrm{wt} . \%)$, while the atomic and mass fractions of nitrogen are 2.32 and 2.66\%, respectively (Figure S4). The subnanosized cobalt can be assumed to exist mainly in the form of a single-atom sites coordinated to nitrogen atoms (cf. [34-36]). The estimated Co fraction is certainly less than that in an area of $\mathrm{Co} @ N C-\mathrm{ZIF}_{\mathrm{SA}}$, containing $\mathrm{Co} / \mathrm{CoO}_{\mathrm{x}}$ nanoparticles $(\sim 6 \mathrm{wt} . \%$, Figure S5), and well below of the average Co content determined by XRF technique (Table 1).

The wide-range XPS spectra confirm the major presence of $\mathrm{Co}, \mathrm{C}, \mathrm{N}$ and $\mathrm{O}$ elements on the surface of Co@NC-ZIF, Co@NC-Gr, Co@NC-ZIF $\mathrm{SA}_{\mathrm{SA}}$ and Co@NC-Gr $\mathrm{SA}_{\mathrm{SA}}$ catalysts (Figure S6). Predictably, no cobalt or nitrogen is present in the samples of Co@C-Gr and NC-Gr, respectively. In the high-resolution Co 2p spectrum, the peaks at 780.6 and $\sim 797 \mathrm{eV}$ can be assigned to $\mathrm{Co}^{2+}$, while the peak at $778.8 \mathrm{eV}$ is related to metallic cobalt (Figure 4a). As expected, the most significant $\mathrm{Co}^{0}$ inclusion is detected in the Co@NC-ZIF and Co@NC$\mathrm{ZIF}_{\mathrm{SA}}$ samples (Table S1 and Table S2). For all the catalysts, the $\mathrm{C} 1$ s region is mainly represented by the peak of graphitic carbon at the binding energy of $284.5 \mathrm{eV}$, while the contribution of $\mathrm{C}=\mathrm{N}(285.8 \mathrm{eV})$ and $\mathrm{C}=\mathrm{O}(288.1 \mathrm{eV})$ bonds, and also carbonates $(290.2 \mathrm{eV})$ is not as considerable (Figure $4 \mathrm{~b}$, Table S3). The N 1s XPS spectrum is resolved into four peaks corresponding to pyridinic $(398.8 \mathrm{eV})$, pyrrolic/graphitic $(400.8 \mathrm{eV})$ and $\mathrm{NO}_{\mathrm{x}}(402.8$, $405.6 \mathrm{eV}$ ) functions (Figure 4c). Their relative contributions are given in Table S4. As it can be seen, the pyridinic- and pyrrolic-graphitic forms of nitrogen are predominant in all the Co@NC catalysts and in the NC-Gr sample. However, their input obviously correlates with the N-ligand taken, and the catalysts based on 1,10-phenanthroline, Co@NC-Gr and Co@NC-GrsA, have a higher percentage of pyridinic nitrogen. The XPS characteristics are fully in line with those of Co@NC materials known in the literature [19-24,27-30,34-37].
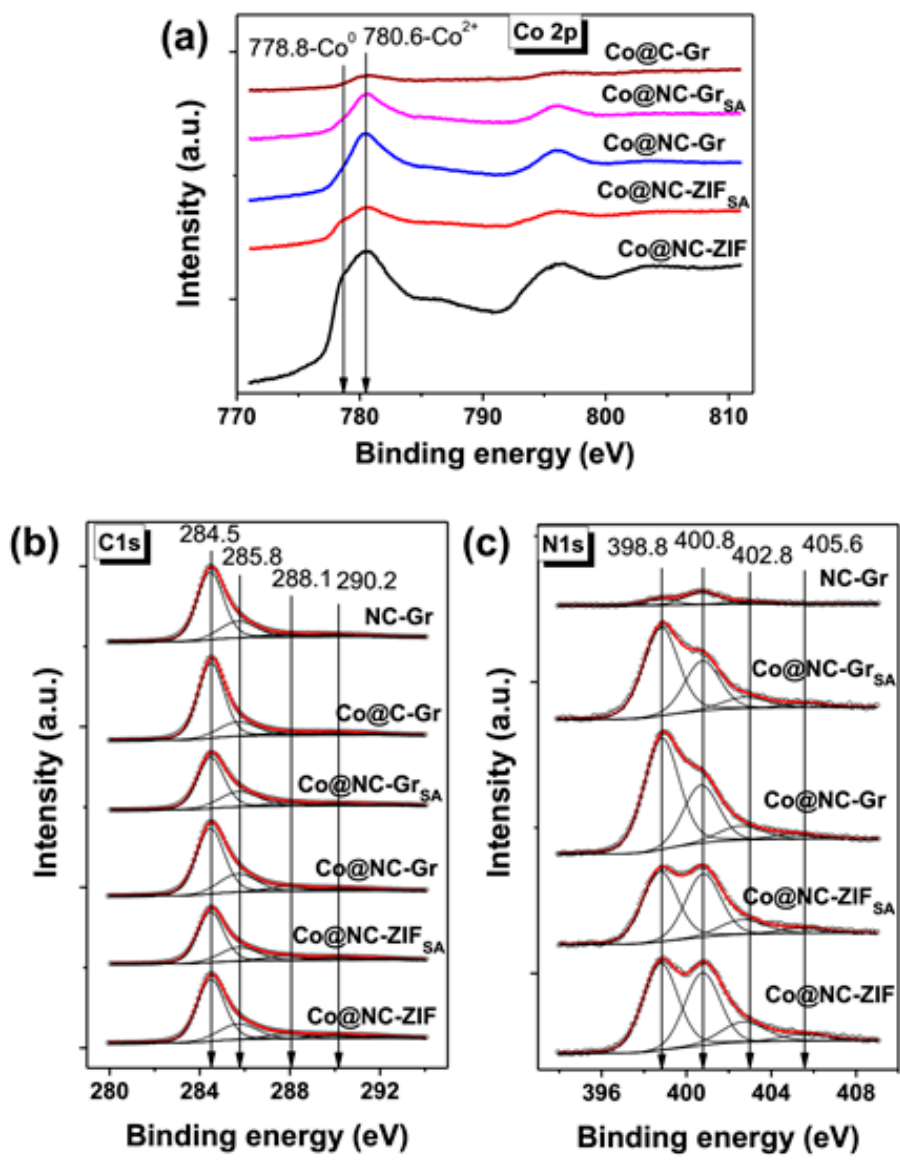

Figure 4. High resolution XPS spectra of (a) Co 2p, (b) C 1s and (c) N 1s of the samples. 
Summarizing the above characterizations and taking into account the relevant literary data [34-36], it can be concluded that the parent samples Co@NC-Gr and Co@NC-ZIF contain significant, though rather different amounts of nano-sized particles of metallic cobalt, and comprise also a uniformly distributed atomically-dispersed cobalt species Co- $\mathrm{N}_{\mathrm{x}}$ in pyridinic/pyrrolic environment. In addition, the Co@NC-ZIF sample contains a considerable amount of cobalt oxides, detectable by XRD, while Co@NC-Gr may include such oxides in a less amount, as revealed by TEM [36]. After leaching these samples with sulfuric acid, the resulting Co@NC-GrsA and Co@NC-ZIF $\mathrm{IA}_{\mathrm{SA}}$ materials consist mainly of graphitic carbon with the inclusion of cobalt single-atomic centers $\left(\mathrm{Co}-\mathrm{N}_{\mathrm{x}}\right)$ which stood intact upon the acid treatment conditions. In addition, Co@NC-ZIF $\mathrm{SA}_{\text {c }}$ contains residual amounts of Co nanoparticles, enveloped by carbon, and nanoparticles of $\mathrm{CoO}_{x}$.

\subsection{Gas-Phase Catalytic Reactions of Ethanol in a Flow Reactor}

Initially, we examined the catalytic performance of the selected samples, Co@NC-Gr, Co@NC-ZIF and Co@NC-ZIF can be seen, formation of acetaldehyde was highly unselective even at a low conversion of ethanol, competing strongly with the deep oxidation pathway already at $200{ }^{\circ} \mathrm{C}$. In contrast to Co@NC-ZIF, Co@NC-ZIF $\mathrm{SA}_{\mathrm{SA}}$ appeared notably more active at the initial range of temperatures, from 200 to $230^{\circ} \mathrm{C}$, but this activity led only to deeper oxidation of ethanol, yielding mainly $\mathrm{CO}_{x}$.

(a)

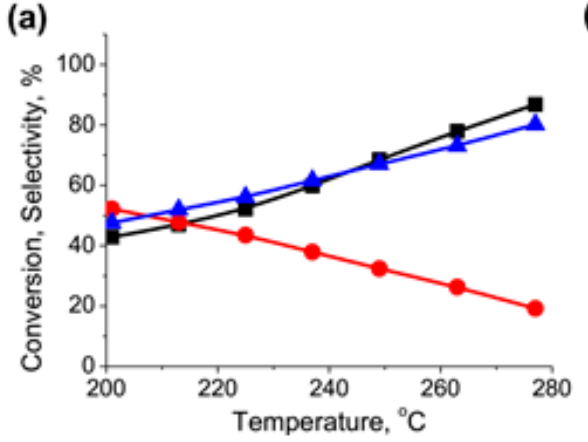

(b)

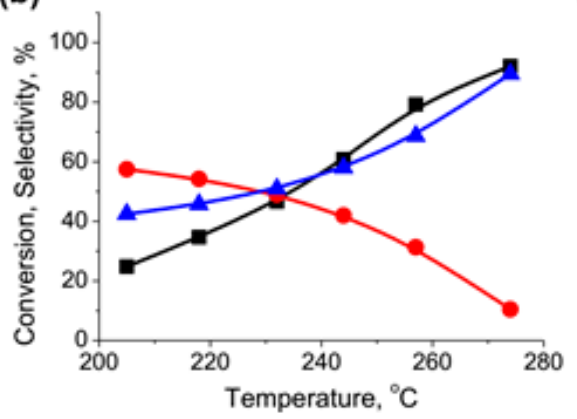

(c)

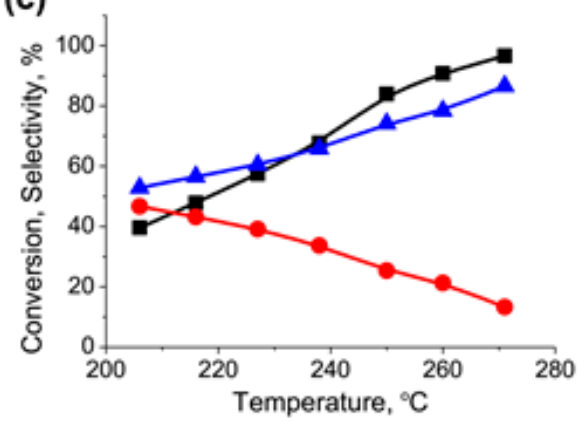

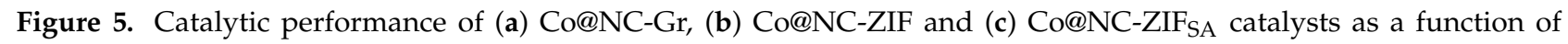
temperature: conversion of ethanol $(\boldsymbol{\square})$ and selectivities toward acetaldehyde $(\bullet)$ and $\mathrm{CO}+\mathrm{CO}_{2}(\boldsymbol{\Delta})$. Gas mixture: 2 vol.\% $\mathrm{EtOH}, 18$ vol. $\% \mathrm{O}_{2}$, He balance; GHSV $\approx 18,000 \mathrm{~h}^{-1}$.

It should be noticed that these findings are quite different from the results on liquid phase aerobic oxidation of alcohols over Co@NC catalysts leading normally to highly efficient oxidative (cross)esterification reactions under comparatively mild conditions $\left(25-60{ }^{\circ} \mathrm{C}\right)[19,27-33]$. However, such difference can be easily understood given the considerably greater concentration of ethanol in the liquid phase, prompting the formation of an intermediate hemiacetal with its further oxidation to an ester. This avoids the alternative reaction pathways occurring in the gas phase.

Figure 6 demonstrates the catalytic performance of Co@NC-Gr, Co@NC-ZIF, Co@NC$\mathrm{Gr}_{\mathrm{SA}}, \mathrm{Co} @ N C-\mathrm{ZIF}_{\mathrm{SA}}, \mathrm{Co} @ \mathrm{C}-\mathrm{Gr}$, and NC-Gr samples in ethanol dehydrogenation under non-oxidative conditions. With the exception of Co@NC-ZIF, these catalysts provide significant selectivity to acetaldehyde at the temperature range of $250-400{ }^{\circ} \mathrm{C}$. However, the catalytic activity of the samples is very different, which is quite evident when considering the corresponding conversions of ethanol on the same graph (Figure S7). It is especially noticeable here that the cobalt-free catalyst, NC-Gr, is the least active compared to others. This indicates the predominant contribution of cobalt species to the target reaction. It should also be noted that the nitrogen-free catalyst, Co@C-Gr, is less active than Co@NC catalysts, confirming a certain role of nitrogen in the catalytic activity. 
(a)

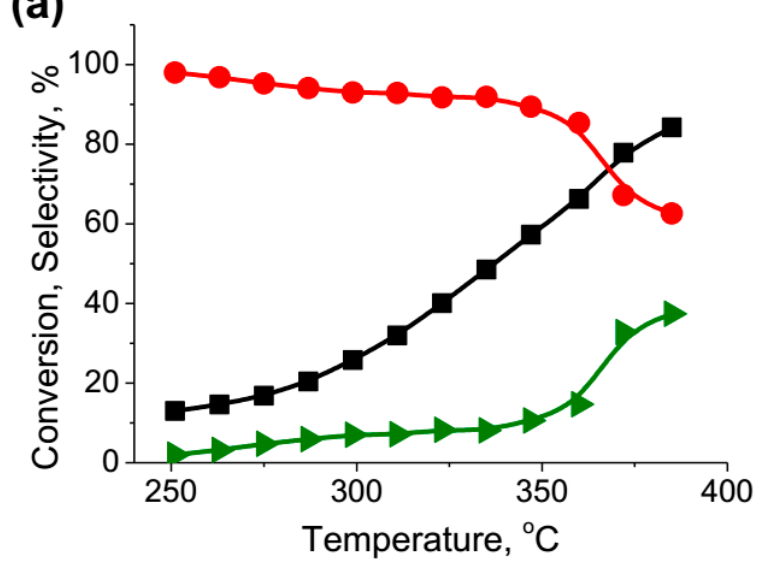

(c)

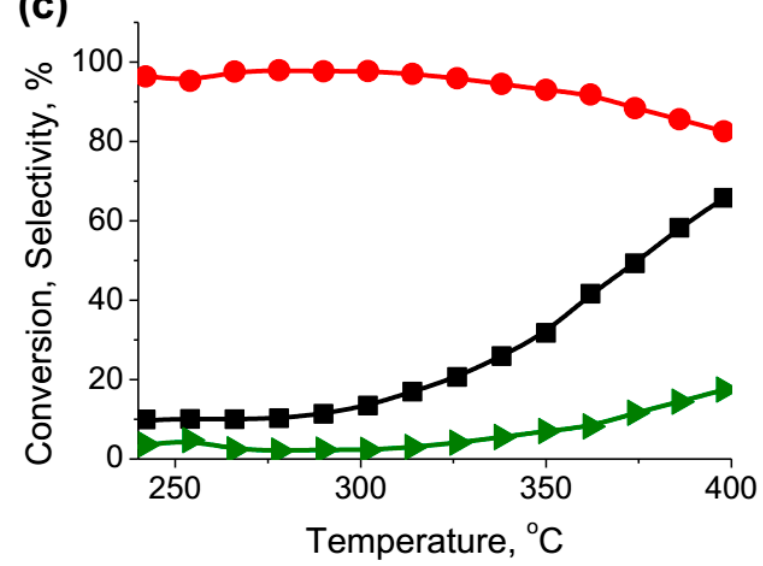

(e)

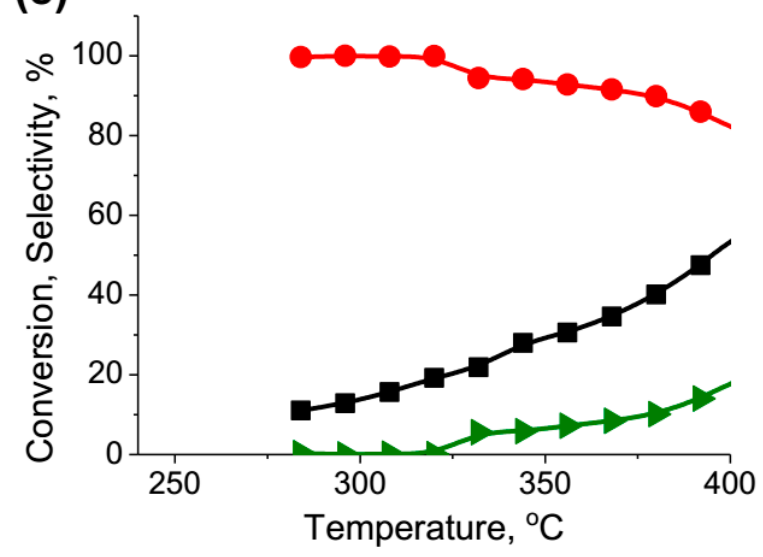

(b)

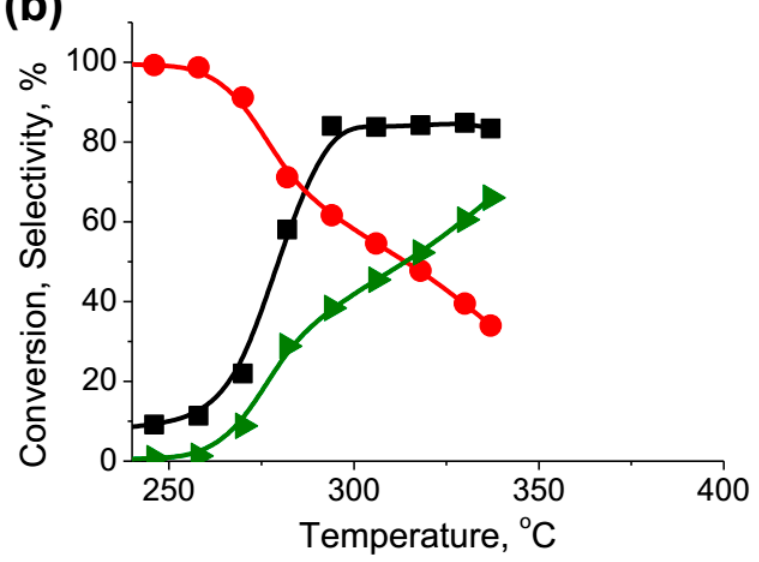

(d)

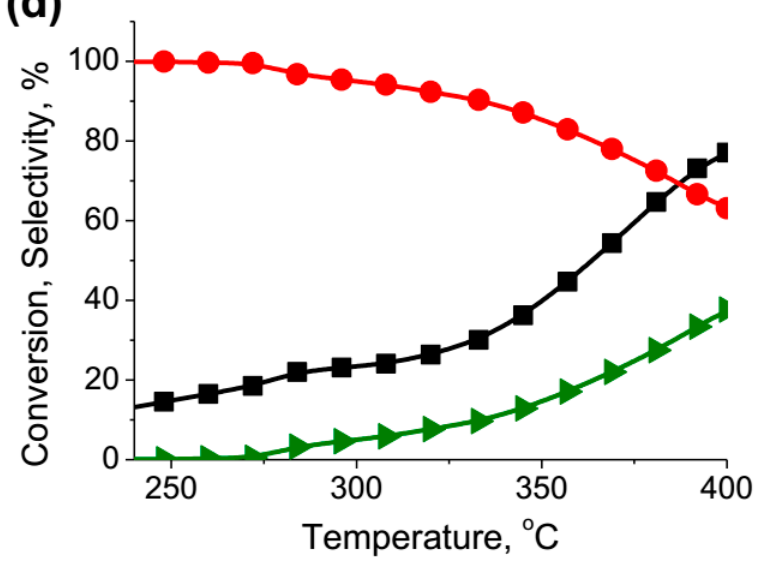

(f)

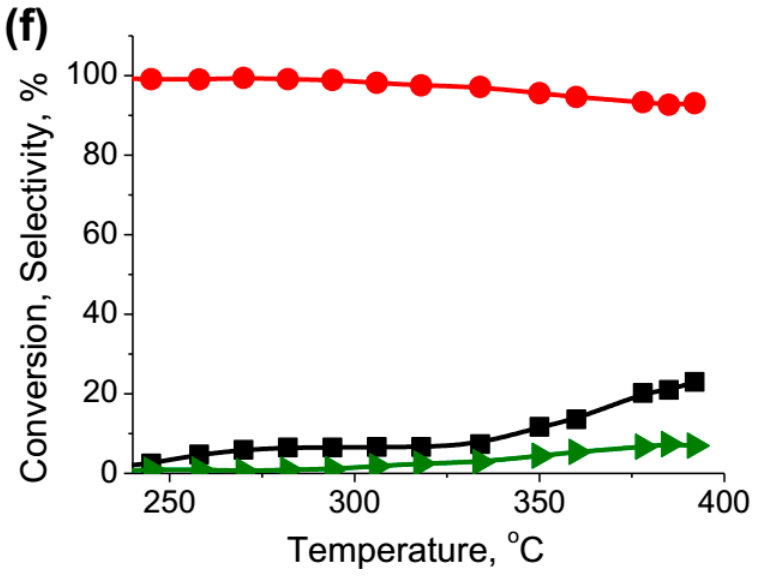

Figure 6. Catalytic performance of (a) Co@NC-Gr, (b) Co@NC-ZIF, (c) Co@NC-GrSA, (d) Co@NC-ZIFSA, (e) Co@C-Gr and (f) NC-Gr catalysts as a function of temperature: conversion of ethanol ( $\square$ ) and selectivities toward acetaldehyde $(\bullet)$ and ethylene $(\triangleright)$. Gas mixture: 5 vol. $\% \mathrm{EtOH}$, He balance; GHSV $\approx 18,000 \mathrm{~h}^{-1}$.

Furthermore, Figure 7 illustrates explicitly that Co@NC-Gr and moreover Co@NC-ZIF samples are more inclined to catalyze ethanol dehydration to ethylene compared to Co@NCGrSA and Co@NC-ZIFSA samples. This is probably due to a higher presence of CoOx species in the parent catalysts. Indeed, cobalt oxides are known to reveal significant Lewis acidity [42] and therefore can initiate an acid-catalyzed conversion of ethanol to ethylene. After sulfuric acid leaching, the obtained Co@NC-GrSA and Co@NC-ZIFSA samples become less active toward ethanol dehydration (Figure $7 \mathrm{~b}$ ). Obviously, this is due to at least partial removal of $\mathrm{CoOx}$ (though along with Co nanoparticles). At the same time, it is clearly 
seen that the removing of Co nanoparticles and CoOx strongly influences the catalytic activity towards ethanol dehydrogenation as well (Figure 7a). For Co@NC-ZIF catalyst, the maximum yield of acetaldehyde, around $50 \%$, is observed at $300{ }^{\circ} \mathrm{C}$, while for Co@NCZIFSA that occurs at $400{ }^{\circ} \mathrm{C}$. A similar tendency also occurs for Co@NC-Gr and Co@NCGrSA samples, which provide the maximum yield of acetaldehyde $(\sim 60 \%)$ at 350 and $450{ }^{\circ} \mathrm{C}$, respectively. These observations may indicate that at a lower temperature, ethanol is dehydrogenated by metal cobalt and cobalt oxide nanoparticles, whereas subnanosized cobalt species are active at higher temperatures and provide better selectively.

(a)

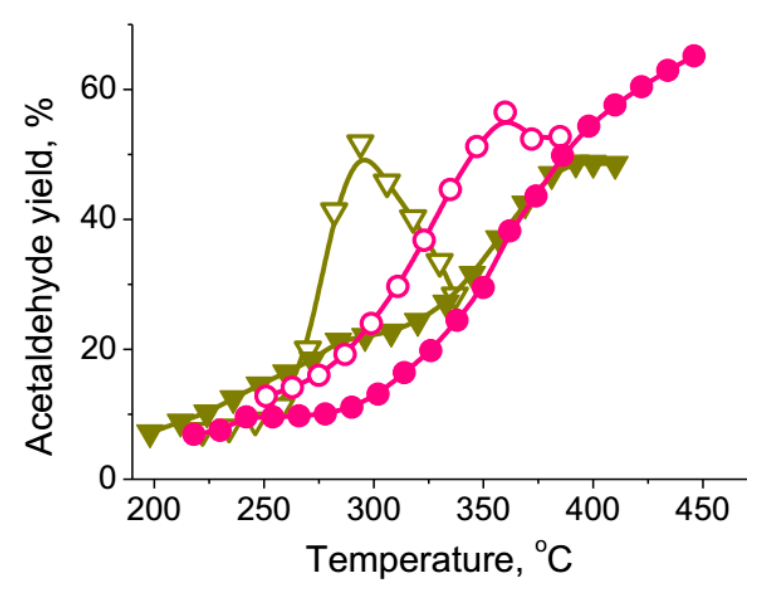

(b)

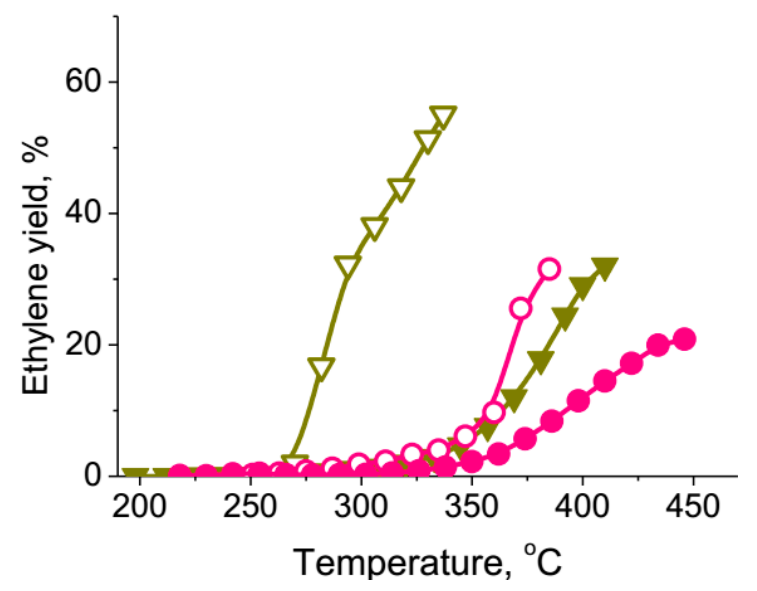

Figure 7. Yields of $(\mathbf{a})$ acetaldehyde and $(\mathbf{b})$ ethylene over Co@NC-Gr $(\bigcirc)$, Co@NC-ZIF $(\nabla)$, Co@NC-GrSA (•) and Co@NC-ZIFSA $(\boldsymbol{\nabla})$ catalysts as a function of temperature. Gas mixture: 5 vol. $\%$ EtOH, He balance; GHSV $\approx 18,000 \mathrm{~h}^{-1}$.

Figure 8 allows a straight comparison of the catalytic activity of Co@NC-Gr, Co@NC-

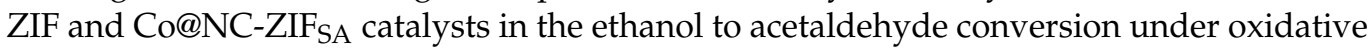
versus non-oxidative reaction conditions. It is clear that in the presence of oxygen, catalytic activity, but not selectivity, is much higher. Notably, such catalytic behaviour is very consistent with that for supported gold and other noble metal catalysts [39,43-45], which was mainly due to the direct involvement of atomic or molecular oxygen species in reaction with ethanol [43] or due to shifting the equilibrium in the dehydrogenation of ethanol through the hydrogen oxidation [39]. Likewise, Co@NC materials, largely known as active catalysts in the oxygen reduction reaction (ORR) [23-25], induce an efficient generation of reactive oxygen species due to the surface mono-atomic Co active sites in pyridinic and pyrrolic environment $[25,46]$. These oxygen forms can oxidize ethanol directly or subsequently react with atomic or molecular hydrogen.
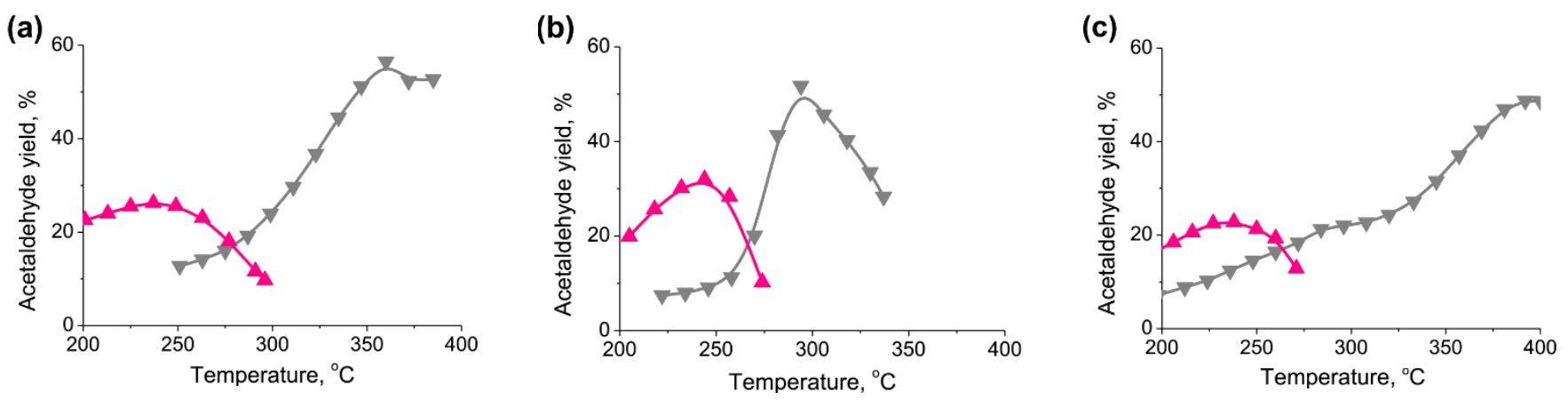

Figure 8. Yields of acetaldehyde over (a) Co@NC-Gr, (b) Co@NC-ZIF and (c) Co@NC-ZIF $\mathrm{SA}$ catalysts as a function

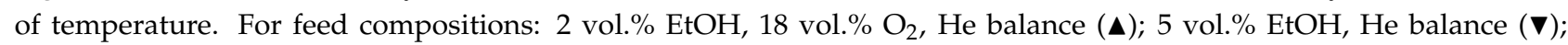
$\mathrm{GHSV} \approx 18,000 \mathrm{~h}^{-1}$. 
Table 1. Catalytic activity of selected carbon based catalysts in ethanol dehydrogenation to acetaldehyde ${ }^{\text {a }}$.

\begin{tabular}{|c|c|c|c|c|}
\hline \multirow[b]{2}{*}{ Catalyst } & \multicolumn{3}{|c|}{ catalyst } & \multirow[b]{2}{*}{ Ref. } \\
\hline & $\begin{array}{c}\text { Reaction } \\
\text { Temperature } \\
\left({ }^{\circ} \mathrm{C}\right)\end{array}$ & $\begin{array}{c}\text { Ethanol } \\
\text { Conversion } \\
(\%)\end{array}$ & $\begin{array}{l}\text { Selectivity to } \\
\text { Acetaldehyde } \\
(\%)\end{array}$ & \\
\hline NC-Gr & 400 & 25 & 91 & This work \\
\hline Co@C-Gr & 400 & 52 & 82 & This work \\
\hline \multirow[t]{2}{*}{$\mathrm{Co} @ \mathrm{NC}-\mathrm{Gr}_{\mathrm{SA}}$} & 400 & 66 & 84 & This work \\
\hline & 300 & 15 & 97 & \\
\hline MCF-C ${ }^{b}$ & 400 & 17 & 80 & [7] \\
\hline $\mathrm{NG}^{\mathrm{c}}$ & 350 & $\sim 10$ & $\sim 100$ & [11] \\
\hline$A C-D^{d}$ & 400 & 48 & 98 & {$[8,47]$} \\
\hline $\mathrm{CNT}^{-\mathrm{AO}^{\mathrm{e}}}$ & 300 & 59 & 97 & [9] \\
\hline $\mathrm{Co} / \mathrm{ACC}^{\mathrm{f}}$ & 400 & 7 & 93 & [15] \\
\hline $4 \% \mathrm{Co} / \mathrm{C}^{\mathrm{g}}$ & 400 & 54 & 92 & [47] \\
\hline $\mathrm{Cu} / \mathrm{ACC}^{\mathrm{h}}$ & 350 & 65 & 96 & [15] \\
\hline $1 \mathrm{Cu} / \mathrm{NMC}-7^{\mathrm{i}}$ & 350 & 57 & 99 & [17] \\
\hline $\mathrm{Cu} / \mathrm{MC}^{\mathrm{j}}$ & 280 & 83 & 95 & [13] \\
\hline $\mathrm{Cu} / \mathrm{C} / \mathrm{SiC}^{\mathrm{k}}$ & 280 & 66 & 99 & [16] \\
\hline
\end{tabular}

a The data refer to non-oxidative gas phase reactions under comparable flow conditions. ${ }^{\mathrm{b}}$ Mesocellular foam carbon. ${ }^{\mathrm{c}}$ Nitrogen-doped graphene nanosheets. ${ }^{\mathrm{d}}$ Activated carbon derived from coffee residue. ${ }^{\mathrm{e}}$ Carbon nanotubes treated with $\mathrm{HNO}_{3}$. The data obtained by the pulsed microcatalytic technique. ${ }^{\mathrm{f}} \mathrm{Co}$ on activated carbon. ${ }^{\mathrm{g}} \mathrm{Co}$ on activated carbon derived from coffee residue. ${ }^{\mathrm{h}} \mathrm{Cu}$ on activated carbon. ${ }^{\mathrm{i}} \mathrm{Cu}$ on $\mathrm{N}$-doped ordered mesoporous carbon. ${ }^{\mathrm{j}} \mathrm{Cu}$ on mesoporous carbon. ${ }^{\mathrm{k}} \mathrm{Cu}$ on carbon/silicon carbide.

A long-term experiment on ethanol dehydrogenation was carried out by the example of Co@NC-GrsA sample, which demonstrated significant catalytic stability (Figure 9). No drop of selectivity to acetaldehyde ( $90 \%)$ at practically constant conversion of ethanol $(\sim 40 \%)$ was observed during $6 \mathrm{~h}$. It indicates that the Co@NC-Gr$r_{S A}$ composite combines the favorable characteristics in terms of its potential use in practice.

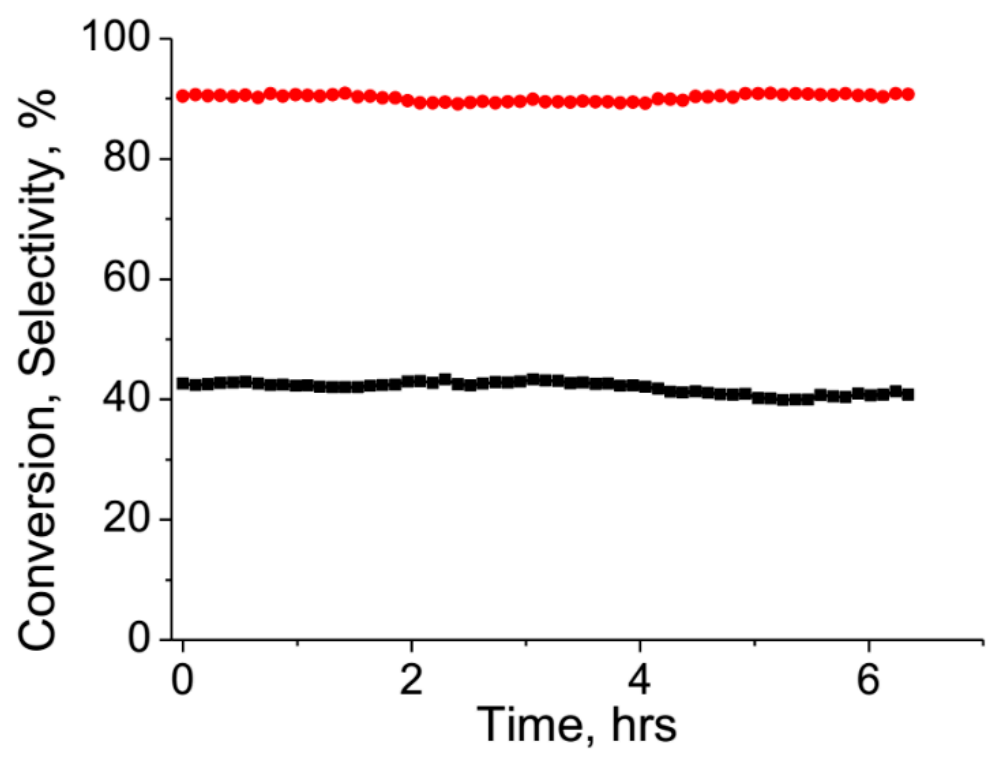

Figure 9. Catalytic performance of Co@NC-Gr $\mathrm{SA}_{\mathrm{SA}}$ catalyst versus reaction time at $365{ }^{\circ} \mathrm{C}$ : conversion of ethanol $(\mathbf{\square})$ and selectivity to acetaldehyde $(\bullet)$. Feed composition: 5 vol.\% EtOH, He balance; $\mathrm{GHSV} \approx 18,000 \mathrm{~h}^{-1}$. 
Finally, a comparative catalytic performance of a set of carbon and selected carbonsupported catalysts in the gas phase dehydrogenation of ethanol is shown in Table 1. Although Co@NC-Gr $\mathrm{SA}_{\mathrm{S}}$ demonstrates an activity and selectivity somewhat inferior to those of the presented $\mathrm{Cu}$-based catalysts, it turns out to be notably more efficient catalyst than the metal-free carbon materials. It is noteworthy also that Co/ACC exhibited a comparatively poor catalytic performance, close to that of purely carbon catalysts. In contrast, $4 \% \mathrm{Co} / \mathrm{C}$ catalyst, derived from coffee residue, showed a much higher catalytic activity [47]. This, however, could be related to the carbon support's own considerable activity, as the parent cobalt-free catalyst AC-D showed a very close activity.

\section{Experimental}

\subsection{Materials}

Cobalt(II) nitrate hexahydrate (Fisher Scientific UK, Loughborough, UK), cobalt(II) acetate tetrahydrate (99.5\%, Vekton, St. Petersburg, Russia), 2-methylimidazole (97\%, Alfa Aesar, Thermo Fisher, Kandel, Germany), 1,10-phenanthroline monohydrate (99\%, SigmaAldrich, Saint Louis, MO, USA) and VulcanXC72R carbon powder (Cabot Carbon Limited, Ellesmere Port, UK) were used as received from the chemical suppliers.

\subsection{Catalysts Preparation}

\subsubsection{Preparation of Co@NC-ZIF and Co@NC-Gr}

The samples denoted as Co@NC-ZIF and Co@NC-Gr were synthesized according to the literature, via a separate ZIF-67 synthesis [30,33] and through the use of solid-state grinding technique [36,37], respectively (Table 2).

Table 2. Characterization data for Co@NC materials.

\begin{tabular}{|c|c|c|c|c|c|c|}
\hline Entry & Catalyst & Cobalt Salt/L ${ }^{a}$ & $\begin{array}{c}\text { Carbon } \\
\text { Support }^{b} \\
\text { (wt. } \%)^{\text {a }}\end{array}$ & $\begin{array}{l}\text { Pyrolysis } \\
\left({ }^{\circ} \mathrm{C}, \mathrm{h}, \mathrm{Gas}\right)\end{array}$ & $\mathrm{Co}^{\mathrm{c}}(w \mathrm{wt} \%)$ & $\begin{array}{c}S_{\mathrm{BET}} \\
\left(\mathrm{m}^{2} \mathrm{~g}^{-1}\right)\end{array}$ \\
\hline 1 & Co@NC-ZIF d & $\mathrm{Co} 2 / \mathrm{L} 2=1: 40$ & - & $850,2, \mathrm{Ar}$ & 32.8 & 174 \\
\hline 2 & Co@NC-ZIF ${ }_{S A}{ }^{e}$ & s & - & - & 10.9 & 507 \\
\hline 3 & Co@NC-Gr ${ }^{\mathrm{f}}$ & $\mathrm{Co} 1 / \mathrm{L} 1=1: 2$ & 65 & $800,2, \mathrm{Ar}$ & 5.0 & 93 \\
\hline 4 & Co@NC-Gr ${ }_{S A}{ }^{e}$ & - & - & - & 1.8 & 45 \\
\hline 5 & Co@C-Gr ${ }^{f}$ & Co1 & 80 & $800,2, \mathrm{Ar}$ & 5.3 & 234 \\
\hline 6 & $N C-G r^{f}$ & L1 & 77 & $800,2, \mathrm{Ar}$ & 0.0 & 202 \\
\hline
\end{tabular}

a Molar ratio. Salts: $\mathrm{Co} 1=\mathrm{Co}(\mathrm{OAc})_{2} \times 4 \mathrm{H}_{2} \mathrm{O} ; \mathrm{Co} 2=\mathrm{Co}\left(\mathrm{NO}_{3}\right)_{2} \times 6 \mathrm{H}_{2} \mathrm{O}$. Ligands: $\mathrm{L} 1=1,10$-phenanthroline $\times$ $1 \mathrm{H}_{2} \mathrm{O}$; $\mathrm{L} 2=2$-methylimidazole. ${ }^{\mathrm{b}}$ VulcanXC72R, weight content before heat treatment. ${ }^{\mathrm{c}}$ Overall Co loading based on XRF analysis. ${ }^{\mathrm{d}} \mathrm{A}$ MOF (ZIF-67)-derived sample. ${ }^{\mathrm{e}}$ The sample after treatment with a $1 \mathrm{M}$ solution of sulfuric acid at $90{ }^{\circ} \mathrm{C}$ for $5 \mathrm{~h}$. ${ }^{\mathrm{f}}$ Sample obtained by the solid-state grinding approach.

\subsubsection{Preparation of Co@NC-ZIFSA and Co@NC-GrSA}

Co@NC-ZIF (1.16 g) was suspended in a $1 \mathrm{M}$ sulfuric acid water solution $(90 \mathrm{~mL})$ at room temperature and after an intensive gas discharge of $5 \mathrm{~min}$, the suspension obtained was stirred at $90{ }^{\circ} \mathrm{C}$ for $5 \mathrm{~h}$. The catalyst was filtered off, washed consecutively with deionized water, followed by $0.3 \mathrm{M} \mathrm{K}_{2} \mathrm{CO}_{3}$ aqueous solution and deionized water until neutral. The solid obtained was dried under vacuum at $80^{\circ} \mathrm{C}$ for $5 \mathrm{~h}$, yielding $0.78 \mathrm{~g}$ of Co@NC-ZIF ${ }_{\mathrm{SA}}$. The sample denoted as Co@NC-Gr $\mathrm{SA}_{\mathrm{SA}}$ was prepared analogously from Co@NC-Gr.

\subsubsection{Preparation of CoC-Gr}

VulcanXC72R carbon $(0.8 \mathrm{~g})$, cobalt(II) nitrate hexahydrate $(0.2 \mathrm{~g})$ and a few drops of water were hand-ground with a pestle in an open mortar for $10 \mathrm{~min}$. The resultant mixture was then heat treated in a ceramic crucible under conditions indicated in Table 2.

\subsubsection{Preparation of NC-Gr}

VulcanXC72R carbon (1.0 g), 1,10-phenanthroline monohydrate $(0.3 \mathrm{~g})$ and a few drops of water were hand-ground with a pestle in an open mortar for $10 \mathrm{~min}$. The resultant 
mixture then underwent thermal processing in a ceramic crucible at conditions shown in Table 2.

\subsection{Catalysts Characterization Techniques}

Catalysts characterization techniques are described in the Supplementary Materials (SI).

\subsection{Catalytic Performance Tests}

The temperature-programmed gas-phase reactions were performed in a quartz tube flow reactor with an internal diameter of $6 \mathrm{~mm}$. Reactions were conducted at atmospheric pressure using a catalyst sample $(200 \mathrm{mg}, \sim 0.2 \mathrm{~mL})$ mixed with quartz sand $(0.5 \mathrm{~mL}$, $\mathrm{d}=0.25 \mathrm{~mm}$ ). The gas mixture of $\mathrm{EtOH} / \mathrm{He}=5 / 95$ or $\mathrm{EtOH} / \mathrm{O}_{2} / \mathrm{He}=1 / 9 / 40$; was fed to the reactor (GHSV $\approx 18,000 \mathrm{~h}^{-1}$, based on the active phase of the catalyst only). The heating rate was $2{ }^{\circ} \mathrm{C} \mathrm{min}^{-1}$. The temperature of reaction $\left( \pm 1^{\circ} \mathrm{C}\right)$ was controlled inside the reactor with a thermocouple placed in the catalyst bed. During the catalyst testing, gas samples were analyzed periodically by integrated online gas chromatography (GC, Tsvet-500; $30 \mathrm{~m} \times 0.32 \mathrm{~mm}$ monolithic poly(divinylbenzene) capillary column; $170{ }^{\circ} \mathrm{C}$ ) with a flame-ionization detector for determination of organics (ethanol, acetaldehyde, acetic acid, ethyl acetate, diethyl ether, ethylene and methane). For determination of carbon oxides, they were preliminarily separated on a $1.5 \mathrm{~m} \times 3 \mathrm{~mm}$ steel column filled with Porapak $\mathrm{Q}$ at $20^{\circ} \mathrm{C}$ followed by methanation. Prior to the catalytic runs, the catalysts were activated at $300{ }^{\circ} \mathrm{C}$ in a flow of helium for $1 \mathrm{~h}$. The reactor was then cooled to $200{ }^{\circ} \mathrm{C}$ and the feed was switched to a mixture of gaseous reagents by $20 \mathrm{~min}$ to reach the steady state initial conditions.

\section{Conclusions}

The catalytic activity of Co@N-doped carbon materials has been studied with regard to the selective dehydrogenation of ethanol to acetaldehyde under both oxidative and non-oxidative gas phase conditions.

It turned out that the presence of oxygen in the reaction feed resulted in a significant contribution of deep oxidation to the reaction, yielding $\mathrm{CO}_{\mathrm{x}}$.

In contrast, non-oxidative conditions appeared more applicable to the target reaction, which is quite selective in the temperature range of 200 to $400{ }^{\circ} \mathrm{C}$, especially at a low content of $\mathrm{CoO}_{x}$ in the catalyst, which catalyze largely the concurrent dehydration of ethanol to ethylene. Removal of $\mathrm{Co}$ and $\mathrm{CoO}_{x}$ nanoparticles by treating of the parent $\mathrm{Co} @ \mathrm{NC}$ catalysts with sulfuric acid led to increased selectivity of reaction to acetaldehyde. Nevertheless, this has led to a simultaneous decrease in catalytic activity in general, indicating partial contribution of $\mathrm{Co}$ and $\mathrm{CoOx}$ nanoparticles to the ethanol non-oxidative dehydrogenation. However, as opposed to the participation of $\mathrm{Co} / \mathrm{CoO}_{x}$ nanoparticles, subnanosized cobalt species (which are single atomic cobalt sites in pyridinic/pyrrolic environment, uniformly distributed in Co@NC catalysts) provide more selective conversion of ethanol to acetaldehyde, though with a higher temperature.

Supplementary Materials: The following are available online at https:/ /www.mdpi.com/article/10 .3390 / catal11111411/s1, Catalysts characterization techniques, Figure S1: TEM images of Co@NCGr, Figure S2: TEM images and EDX analysis of Co@NC-ZIF, Figure S3: EDX-STEM mixed Co/C

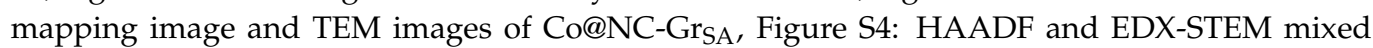

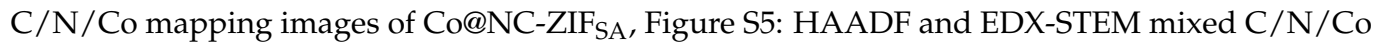
and $\mathrm{O}$ mapping images of $\mathrm{Co} @ \mathrm{NC}-\mathrm{ZIF}_{\mathrm{SA}}$ for the area containing $\mathrm{Co} / \mathrm{CoO}_{\mathrm{x}}$ nanoparticles, Figure S6: Survey XPS of the samples, Figure S7: Conversions of ethanol under non-oxidative conditions as a function of temperature, Table S1: The XPS-derived chemical composition of the samples, Table S2: The XPS-derived atomic fractions of elements in the samples, Table S3: The relative contribution of carbon species in the $\mathrm{N} 1$ s spectra, Table S4: The relative contribution of nitrogen species in the C $1 \mathrm{~s}$ spectra, Table S5: Textural parameters of the samples. 
Author Contributions: A.N.C.: Investigation. T.V.A.: Investigation. K.Y.K.: Data curation, Writingoriginal draft. V.I.S.: Investigation, Data curation, Supervision. All authors have read and agreed to the published version of the manuscript.

Funding: This work was supported by the Ministry of Science and Higher Education of the Russian Federation within the governmental order for Boreskov Institute of Catalysis (project AAAA-A21121011390008-4).

Data Availability Statement: The results presented in this work were not previously published anywhere.

Acknowledgments: The studies were carried out using facilities of the shared research center "National center of investigation of catalysts" at Boreskov Institute of Catalysis.

Conflicts of Interest: The authors declare that they have no known competing financial interest or personal relationships that could have appeared to influence the work reported in this paper.

\section{References}

1. Serrano-Ruiz, J.C.; Luque, R.A. Sepulveda-Escribano, Transformations of biomass-derived platform molecules: From high added-value chemicals to fuels via aqueous-phase processing. Chem. Soc. Rev. 2011, 40, 5266-5281. [CrossRef] [PubMed]

2. Farmer, T.J.; Mascal, M. Platform Molecules. In Introduction to Chemicals from Biomass; Clark, J., Deswarte, F., Eds.; John Wiley \& Sons Ltd.: Hoboken, NJ, USA, 2015; pp. 89-155. [CrossRef]

3. Angelici, C.; Weckhuysen, B.M.; Bruijnincx, P.C.A. Chemocatalytic Conversion of Ethanol into Butadiene and Other Bulk Chemicals. ChemSusChem 2013, 6, 1595-1614. [CrossRef]

4. Abdulrazzaq, H.T.; Schwartz, T.J. Catalytic Conversion of Ethanol to Commodity and Specialty Chemicals. In Ethanol: Science and Engineering; Basile, A., Adolfo, I., Francesco, D., Nejat, V.T., Eds.; Elsevier: Amsterdam, The Netherlands, 2019 ; pp. 3-24. [CrossRef]

5. Grim, R.G.; To, A.T.; Farberow, C.A.; Hensley, J.E.; Ruddy, D.A.; Schaidle, J.A. Growing the Bioeconomy through Catalysis: A Review of Recent Advancements in the Production of Fuels and Chemicals from Syngas-Derived Oxygenates. ACS Catal. 2019, 9 , 4145-4172. [CrossRef]

6. Szymanski, G.S.; Rychlicki, G.; Terzyk, A.P. Catalytic conversion of ethanol on carbon catalysts. Carbon 1994, 32, 265-271. [CrossRef]

7. Klinthongchai, Y.; Prichanont, S.; Praserthdam, P.; Jongsomjit, B. Synthesis, characteristics and application of mesocellular foam carbon (MCF-C) as catalyst for dehydrogenation of ethanol to acetaldehyde. J. Environ. Chem. Eng. 2020, 8, 103752. [CrossRef]

8. Ob-eye, J.; Praserthdam, P.; Jongsomjit, B. Ethanol Dehydrogenation to Acetaldehyde over Activated Carbons-Derived from Coffee Residue. Bull. Chem. React. Eng. Catal. 2019, 14, 268-282. [CrossRef]

9. Tveritinova, E.A.; Zhitnev, Y.N.; Chernyak, S.A.; Arkhipova, E.A.; Savilov, S.V.; Lunin, V.V. Catalytic Conversion of Aliphatic Alcohols on Carbon Nanomaterials: The Roles of Structure and Surface Functional Groups. Russ. J. Phys. Chem. A 2017, 91, 448-454. [CrossRef]

10. Jasińska, J.; Krzyżyńska, B.; Kozłowski, M. Influence of activated carbon modifications on their catalytic activity in methanol and ethanol conversion reactions. Cent. Eur. J. Chem. 2011, 9, 925-931. [CrossRef]

11. Li, S.; Wang, W.; Liu, X.; Zeng, X.; Li, W.; Tsubaki, N.; Yu, S. Nitrogen-doped graphene nanosheets as metal-free catalysts for dehydrogenation reaction of ethanol. RSC Adv. 2016, 6, 13450-13455. [CrossRef]

12. Grunewald, G.C.; Drago, R.S. Carbon Molecular Sieves as Catalysts and Catalyst Supports. J. Am. Chem. Soc. 1991, 113, 1636-1639. [CrossRef]

13. Wang, Q.-N.; Shi, L.; Lu, A.-H. Highly Selective Copper Catalyst Supported on Mesoporous Carbon for the Dehydrogenation of Ethanol to Acetaldehyde. ChemCatChem 2015, 7, 2846-2852. [CrossRef]

14. Lu, W.-D.; Wang, Q.-N.; He, L.; Li, W.-C.; Schuth, F.; Lu, A.-H. Copper Supported on Hybrid C@SiO 2 Hollow Submicron Spheres as Active Ethanol Dehydrogenation Catalyst. ChemNanoMat 2018, 4, 505-509. [CrossRef]

15. Ob-eye, J.; Praserthdam, P.; Jongsomjit, B. Dehydrogenation of Ethanol to Acetaldehyde over Different Metals Supported on Carbon Catalysts. Catalysts 2019, 9, 66. [CrossRef]

16. Li, M.-Y.; Lu, W.-D.; He, L.; Schüth, F.; Lu, A.-H. Tailoring the Surface Structure of Silicon Carbide Support for Copper Catalyzed Ethanol Dehydrogenation. ChemCatChem 2019, 11, 481-487. [CrossRef]

17. Thumbayil, R.P.; Christensen, D.B.; Mielby, J.; Kegnæs, S. Dehydrogenation of bioethanol using Cu nanoparticles supported on $\mathrm{N}$-doped ordered mesoporous carbon. ChemCatChem 2020, 12, 5644-5655. [CrossRef]

18. Liu, L.; Corma, A. Metal Catalysts for Heterogeneous Catalysis: From Single Atoms to Nanoclusters and Nanoparticles. Chem. Rev. 2018, 118, 4981-5079. [CrossRef] [PubMed]

19. Xie, J.; Kammert, J.D.; Kaylor, N.; Zheng, J.W.; Choi, E.; Pham, H.N.; Sang, X.; Stavitski, E.; Attenkofer, K.; Unocic, R.R.; et al. Atomically Dispersed Co and Cu on N-Doped Carbon for Reactions Involving C-H Activation. ACS Catal. 2018, 8, 3875-3884. [CrossRef] 
20. Cui, X.; Li, Y.; Bachmann, S.; Scalone, M.; Surkus, A.-E.; Junge, K.; Topf, C.; Beller, M. Synthesis and Characterization of Iron-Nitrogen-Doped Graphene/Core-Shell Catalysts: Efficient Oxidative Dehydrogenation of N-Heterocycles. J. Am. Chem. Soc. 2015, 137, 10652-10658. [CrossRef]

21. Iosub, A.V.; Stahl, S.S. Catalytic Aerobic Dehydrogenation of Nitrogen Heterocycles Using Heterogeneous Cobalt Oxide Supported on Nitrogen-Doped Carbon. Org. Lett. 2015, 17, 4404-4407. [CrossRef]

22. Banerjee, D.; Jagadeesh, R.V.; Junge, K.; Pohl, M.-M.; Radnik, J.; Bruckner, A.; Beller, M. Convenient and Mild Epoxidation of Alkenes Using Heterogeneous Cobalt Oxide Catalysts. Angew. Chem. Int. Ed. 2014, 53, 4359-4363. [CrossRef]

23. Zhang, M.; Zhang, E.; Hu, C.; Zhao, Y.; Zhang, H.; Zhang, Y.; Ji, M.; Yu, J.; Cong, G.; Liu, H.; et al. Controlled Synthesis of Co@N-Doped Carbon by Pyrolysis of ZIF with 2-Aminobenzimidazole Ligand for Enhancing Oxygen Reduction Reaction and the Application in Zn-Air Battery. ACS Appl. Mater. Interfaces 2020, 12, 11693-11701. [CrossRef] [PubMed]

24. Wang, X.; Fu, H.; Li, W.; Zheng, J.; Li, X. Metal (metal = Fe, Co), N codoped nanoporous carbon for efficient electrochemical oxygen reduction. RSC Adv. 2014, 4, 37779-37785. [CrossRef]

25. Sahraie, N.R.; Kramm, U.I.; Steinberg, J.; Zhang, Y.; Thomas, A.; Reier, T.; Paraknowitsch, J.-P.; Strasser, P. Quantifying the density and utilization of active sites in non-precious metal oxygen electroreduction catalysts. Nat. Commun. 2015, 6, 8618. [CrossRef] [PubMed]

26. Morozan, A.; Goellner, V.; Nedellec, Y.; Hannauer, J.; Jaouen, F. Effect of the Transition Metal on Metal-Nitrogen-Carbon Catalysts for the Hydrogen Evolution Reaction. J. Electrochem. Soc. 2015, 162, H719-H726. [CrossRef]

27. Jagadeesh, R.V.; Junge, H.; Pohl, M.-M.; Radnik, J.; Brückner, A.; Beller, M. Selective oxidation of alcohols to esters using heterogeneous $\mathrm{Co}_{3} \mathrm{O}_{4}-\mathrm{N} @ \mathrm{C}$ catalysts under mild conditions. J. Am. Chem. Soc. 2013, 135, 10776-10782. [CrossRef]

28. Su, H.; Zhang, K.-X.; Zhang, B.; Wang, H.-H.; Yu, Q.-Y.; Li, X.-H.; Antonietti, M.; Chen, J.-S. Activating cobalt nanoparticles via the Mott-Schottky effect in nitrogen rich carbon shells for base-free aerobic oxidation of alcohols to esters. J. Am. Chem. Soc. 2017, 139, 811-818. [CrossRef]

29. Zhong, W.; Liu, H.; Bai, C.; Liao, S.; Li, Y. Base-free oxidation of alcohols to esters at room temperature and atmospheric conditions using nanoscale co-based catalysts. ACS Catal. 2015, 5, 1850-1863. [CrossRef]

30. Zhou, Y.-X.; Chen, Y.-Z.; Cao, L.; Lu, J.; Giang, H.-L. Conversion of a metal-organic framework to N-doped porous carbon incorporating Co and CoO nanoparticles: Direct oxidation of alcohols to esters. Chem. Commun. 2015, 51, 8292-8295. [CrossRef]

31. Eisenberg, D.; Slot, T.K.; Rothenberg, G. Understanding oxygen activation on metal- and nitrogen-codoped carbon catalysts. ACS Catal. 2018, 8, 8618-8629. [CrossRef]

32. Yasukawa, T.; Yang, X.; Kobayashi, S. Development of N-doped carbon-supported cobalt/copper bimetallic nanoparticle catalysts for aerobic oxidative esterifications based on polymer incarceration methods. Org. Lett. 2018, 20, 5172-5176. [CrossRef]

33. Astrakova, T.V.; Chernov, A.N.; Sobolev, V.I.; Koltunov, K.Y. Effect of bases on catalytic properties of cobalt-nitrogen-carbon composites in oxidative esterification of benzyl alcohol with methanol. Russ. J. Appl. Chem. 2019, 92, 295-299. [CrossRef]

34. Tang, C.; Surkus, A.-E.; Chen, F.; Pohl, M.-M.; Agostini, G.; Schneider, M.; Junge, H.; Beller, M. A stable nanocobalt catalyst with highly dispersed CoNx active sites for the selective dehydrogenation of formic acid. Angew. Chem. Int. Ed. 2017, 56, 16616-16620. [CrossRef] [PubMed]

35. Li, X.; Surkus, A.-E.; Rabeah, J.; Anwar, M.; Dastigir, S.; Junge, H.; Bruckner, A.; Beller, M. Cobalt Single-Atom Catalysts with High Stability for Selective Dehydrogenation of Formic Acid. Angew. Chem. Int. Ed. 2020, 59, 15849-15854. [CrossRef] [PubMed]

36. Chernov, A.N.; Astrakova, T.V.; Sobolev, V.I.; Koltunov, K.Y. Liquid versus gas phase dehydrogenation of formic acid over Co@N-doped carbon materials. The role of single atomic sites. Mol. Catal. 2021, 504, 111457. [CrossRef]

37. Astrakova, T.V.; Sobolev, V.I.; Koltunov, K.Y. Facile mechanochemical synthesis of Co@NC catalysts for oxidative esterification of benzyl alcohol with methanol. Catal. Commun. 2020, 137, 105952. [CrossRef]

38. Sobolev, V.I.; Koltunov, K.Y. MoVNbTe Mixed Oxides as Efficient Catalyst for Selective Oxidation of Ethanol to Acetic Acid. ChemCatChem 2011, 3, 1143-1145. [CrossRef]

39. Sobolev, V.I.; Koltunov, K.Y.; Simakova, O.A.; Leino, A.-R.; Murzin, D.Y. Low temperature gas-phase oxidation of ethanol over $\mathrm{Au} / \mathrm{TiO}_{2}$. Appl. Catal. A 2012, 433-434, 88-95. [CrossRef]

40. Vodyankina, O.V.; Blokhina, A.S.; Kurzina, I.A.; Sobolev, V.I.; Koltunov, K.Y.; Chukhlomina, L.N.; Dvilis, E.S. Selective oxidation of alcohols over Ag-containing $\mathrm{Si}_{3} \mathrm{~N}_{4}$ catalysts. Catal. Today 2013, 203, 127-132. [CrossRef]

41. Li, Z.Q.; Lu, C.J.; Xia, Z.P.; Zhou, Y.; Luo, Z. X-ray diffraction patterns of graphite and turbostratic carbon. Carbon 2007, 45, 1686-1695. [CrossRef]

42. Mekhemer, G.A.H.; Abd-Allah, H.M.M.; Mansour, S.A.A. Surface characterization of silica-supported cobalt oxide catalysts. Coll. Surf. A 1999, 160, 251-259. [CrossRef]

43. Guan, Y.; Hensen, E.J.M. Ethanol dehydrogenation by gold catalysts: The effect of the gold particle size and the presence of oxygen. Appl. Catal. A 2009, 361, 49-56. [CrossRef]

44. Blokhinaa, A.S.; Kurzina, I.A.; Sobolev, V.I.; Koltunov, K.Y.; Mamontov, G.V.; Vodyankina, O.V. Selective Oxidation of Alcohols over $\mathrm{Si}_{3} \mathrm{~N}_{4}$ Supported Silver Catalysts. Kinet. Catal. 2012, 53, 477-481. [CrossRef]

45. Torbina, V.V.; Vodyankin, A.A.; Ten, S.; Mamontov, G.V.; Salaev, M.A.; Sobolev, V.I.; Vodyankina, O.V. Ag-Based Catalysts in Heterogeneous Selective Oxidation of Alcohols: A Review. Catalysts 2018, 8, 447. [CrossRef] 
46. Cheng, Q.; Han, S.; Mao, K.; Chen, C.; Yang, L.; Zou, Z.; Guc, M.; Hu, Z.; Yang, H. Co nanoparticle embedded in atomicallydispersed Co-N-C nanofibers for oxygen reduction with high activity and remarkable durability. Nano Energy 2018, 52, 485-493. [CrossRef]

47. Ob-Eye, J.; Jongsomjit, B. Dehydrogenation of ethanol to acetaldehyde over Co/C catalysts. Eng. J. 2019, 23, 1-13. [CrossRef] 